\title{
Polyurethane compositions of Bismuth used for breast shields during chest CT
}

\author{
P. Mehnati', M. Arashi ${ }^{*}$, M.S. Zakerhamidi², M. Ghavami3 \\ ${ }^{1}$ Medical Radiation Sciences Research team, School of Medicine, Tabriz University of Medical Sciences, Tabriz, Iran \\ ${ }^{2}$ Research Institute for Applied Physics and Astronomy, Tabriz University, Tabriz, Iran \\ ${ }^{3}$ Department of Radiology, School of Medicine, Tabriz University of Medical Sciences, Tabriz, Iran
}

\section{ABSTRACT}

\section{- Original article}

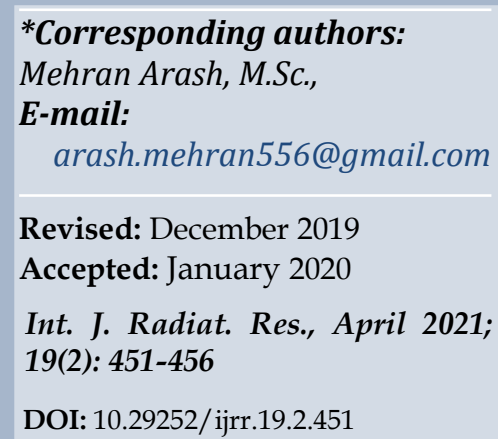

\begin{abstract}
Background: Bismuth Polyurethane composite is a novel shield for breast protection while saving image quality in chest CT. Bismuth different concentrations used for constructing polymer composites breast shields in this study. Materials and Methods: Bismuth with particle size <150 micrometer used in bismuth polyurethane composite (BPC) with a ratio of $10 \%, 15 \%$ and 1.1, $2.2 \mathrm{~mm}$ thicknesses. The BPC was examined on the female chest phantom (skin and fourth layers), $120 \mathrm{kV}$ and $80 \mathrm{~mA}$ selected as an exposure factors in chest CT. The dose reduction was recorded by TLD and the image quality was evaluated quantitatively and quantitatively. Results: Using BPC shields $10 \%$ and $15 \%$ (2.2 $\mathrm{mm}$ ) induced to breast dose reduction to $69.1 \%$ and $\mathbf{7 7 . 5 \%}$ for skin layer and $44.7 \%$ and $52.8 \%$ for fourth layer, respectively. The image noise Increasing in BPC for breast and mediastinum areas were 9.43\% ( $P=0.347)$ and $15.44 \%(P=0.386)$, respectively. Conclusion: Application of Bismuth with different weight ratios in polyurethane composite was useful shield for radiation dose reduction of the breast in chest CT.
\end{abstract}

Keywords: Breast shield, chest CT, bismuth polyurethane construction.

\section{INTRODUCTION}

Nowadays, chest CT is used as a valuable tool for noninvasive assessment of mediastinum, lungs and heart disease (1). Replacing chest X-ray in modern radiology, chest CT scans play an important role in the diagnosis and management of patients in critical medical conditions. The biological effects of chest CT are thought to be negligible, but in sensitive organs such as the lung, heart and especially the breast in younger women, it induces high risks of cancer. In the thorax, CT often causes the breast to be exposed to high doses of radiation during the imaging procedure (2-5). On the other hand, breast cancer is the most common cause of malignant disease in women worldwide, with radiation acting as a possible cauasative factor. In comparing chest computer tomography and chest X-ray doses, the ratio between lung dose in CT and radiography, for example, turned out to be 11.56 (6).
Three accepted methods are available to protect and reduce breast radiation dose. One is the distance between the source of radiation and the sensitive organs. Another is inverse-square law (ISL), but ISL is limited in CT due to constant distance between the X-ray tube and the location of the patient in the gantry device. Still another involves minimizing exposure time, and its selection must be made by considering other expoture factors in patient imaging.

The shields are one of the selective and importante ways to obtain of the radiation protection during chest $\mathrm{CT}$. In ionising imaging centers Lead shields are usually used. This heavy metal covers the organ, protecting it against radiation, but it is at the cost of the organ image. This motivated the researchers to design and construct lead free shields containing bismuth cadmium (Cd), tin ( $\mathrm{Sn})$, barium (Ba), tungsten (W) with $\mathrm{K}$ absorption edge from 40 to $120 \mathrm{kV}$ (7).

In most articles of chest CT, what is 
introduced and used are commercial Bismuth shields for the breast made by certain companies (attenurad, F\&L medical Co) $(2,4,8,9)$. Recently, some shields were designed and constructed that included composites of Barium sulfate $\left(\mathrm{BaSO}_{4}\right)$ with filler particles of bismuth oxide $\left(\mathrm{Bi}_{2} \mathrm{O}_{3}\right)$ in different thicknesses $(0.5$ to 2 $\mathrm{mm}$ ). These shields were applied in chest CT and showed dose reduction from $13.56 \%$ to $66.64 \%$ depending on $\mathrm{kV}$ and shield thickness (10). In the som articles, structure and details of the materials combiend and used in the shields are presented without further explainations about their; some only point to changing of foam thickness to reduce distortion or artifacts on the chest images $(11,12)$. In the chest CT by the pediatric and adult phantoms, a decline of breast doses of $21 \%$ and $\% 37$, respectively, using Bismuth shield has been possible (13). Researchers in 2016 revealed about 28.5\% decrease in the eye lens dose in head CT (in contact shield) with no especial artifact (14). Non lead shields, especially bismuth, are best for superficial organs such as the breast, thyroid and lens (15). Using bismuth shields in MDCT for pediatrics, the succeded study in reducing breast dose by $29 \%$ found no statistically significant differences in noise between the shielded and non-shielded lung images (16). Also two studies using Bismuth shields reported 30\% (17) and $45 \%{ }^{(18)}$ dose reduction in the breast.

The aim of this study was introduce of bismuth polyurethane matrixes as a new shield for potentially protection of breast during chest CTscan examine within image quality study. In this study polymer composite of bismuth polyurethane with different weighting factor and thickness were used for presenting weighting factors and thicknesses effects of new design composite on the chest CT scan dose. The novelty of this work is the new compound material of the shield as well as different weighting factor and thickness.

\section{MATERIALS AND METHODS}

Polyurethane was as a matrix with in microparticles of bismuth micrometer metal beads (size <150, Merck Germany;12400 Code).

Polyurethane made by alleles formulation (including several hydroxyl groups, $\mathrm{OH}$ is a type of alcohol) as well as isocyanate, an organic compound with the general formula $\mathrm{RN}-\mathrm{C}=\mathrm{O}$ (SELSIL, Turkey).

Bismuth polyurethane composite (BPC) shields were designed and constructed with $10 \%$ and $15 \%$ of Bismuth metal concentration $(210 \times 210 \mathrm{~mm})$, with thickness of 1.1 and 2.2 mm shield.

\section{Phantom and dosimetry}

The chest phantom in layered form for female was used that constructed before (19). Dose reduction was measured by thermoluminescent dosimeters (TLD) (LiF: Mg, Ti dosimeters GR-200) on the skin layer (SL) and in the fourth layer (FL) of the breast in the phantom. For preparing, the 35 TLDs (GR -200) were calibrated in the Pars Isotope dosimetric laboratory (Tehran, Iran) in the range of usually used energy in CT scan (80, 100, 120 and 140 $\mathrm{kVp}$ ), and then annealed in the thermal oven to remove the remaining and undesired signals and increase the sensitivity. Also to prevent image artifacts one $\mathrm{cm}$ of foam was placed under the shields on the breast phantom.

In supine position, the phantom was placed in the gantry isocenter for chest CT scan. Similar scanning parameters were selected to be used for the chest CT of the patient (tube voltage 120 $\mathrm{kv}$, tube curent $80 \mathrm{mAs}$, slice thickness $10 \mathrm{~mm}$ and a pitch of 1.3). The first stage of scaning, the topogram phase, was performed without a shield. The shields were used after topogram to prevent automatic dose increase due to shield thickness, with AEC method working as a result of the shield being present on the breast.

For linear attenuation coefficient $(\mu)$ and the mass attenuation coefficient $(\mu / \rho)$ in the $120 \mathrm{kV}$ and $80 \mathrm{mAs}$ were calculated as well as dose measurment was carried out with the presence of the shield by Diadose (PTW).

\section{Image quality}

The region of the right and left breast and body phantom of the chest images were taken in the quantitative measurements through

Int. J. Radiat. Res., Vol. 19 No. 2, April 2021 
determining image noise and Contrast Noise Ratio (CNR).

A radiologist with 10 years of experience qualified the chest CT images requested for the qualitative imaging process, with and without the shield in chest CT images. Image noise evaluation was performed as detailed explained in article (20).

For data analyses, Kruskal-Wallis and Mann-Whitney Statistical tests with SPSS16 were used.

\section{RESULTS}

\section{Bismuth composite shields linear attenuation cofficient $(\mu)$ and mass attenuation cofficient $(\mu / \rho)$}

Linear attenuation coefficient $(\mu)$ and mass attenuation coefficient $(\mu / \rho)$ values of BPC were different with the same thickness of 1.1 and 2.2 $\mathrm{mm}$ in the shields. The $\mu$ for BPC $10 \%$ were 7.26 $\mathrm{cm}^{-1}$ and for BPC $15 \%$ were $8.68 \mathrm{~cm}^{-1}$, as shown in figure 1 . The $\mu / \rho$ for BPC $10 \%$ were $6.61 \mathrm{~cm}^{2} /$ gr and for BPC $15 \%$ were $7.81 \mathrm{~cm}^{2} / \mathrm{gr}$, as shown in figure 2 .

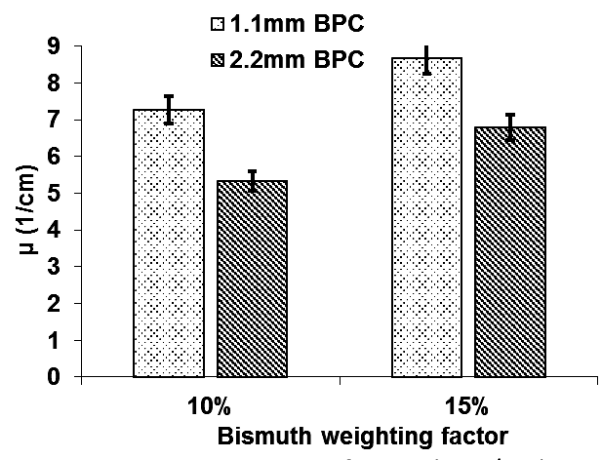

Figure 1. Linear attenuation coefficient $(\mu, 1 / \mathrm{cm})$ with $( \pm S D)$ was shown. For in BPC (Bismuth Polyurethane Composite) shields in 1.1 and $2.2 \mathrm{~mm}$ thicknesses on the chest phantom during Chest CT.

\section{Meausurment of breast dose using BPC shield in skin and fourth layers}

In the absent of the shield the breast dose in the skin layer was $8.32 \pm 2.03 \mathrm{mSv}$ and in the fourth layer was $7.63 \pm 1.20 \mathrm{mSv}$ from recorted data by TLD. Application of 10 and 15 percent BPC shields with a thickness of $1.1 \mathrm{~mm}$ in the skin layer caused breast dose decline to $55 \%$ and 61.5\%, respectively (table 1). Also, application of BPC shields from 10 and 15 percent induced reductions of $43.3 \%$ to $47.9 \%$ in the fourth layer of breast dose, respectively. When the thickness went up to $2.2 \mathrm{~mm}$ using BPC shields 10 and 15 percent, the breast dose reduction in skin and fourth layers increased as shown in detail in table 1 . Also, a significant difference was observed with BPC $10 \%$ and $15 \%$ with a thickness of $1.1 \mathrm{~mm}$ in comparison to the without-shield condition $(\mathrm{p}<0.05)$. Therefore, when considering the percentage of the Bismuth in the shields, breast radiation dose will be significantly lower in comparison to the without-shields condition $(\mathrm{p}<0.05)$.

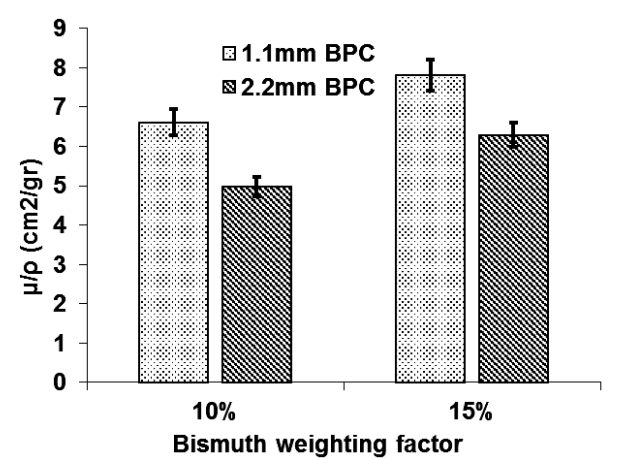

Figure 2. Mass attenuation coefficient $(\mu / \rho, \mathrm{cm} 2 / \mathrm{gr})$ with $( \pm S D)$ was shown. For in BSC (Bismuth Polyurethane Composite) shields in 1.1 and $2.2 \mathrm{~mm}$ thicknesses on the chest phantom during Chest CT.

Table 1. Assessment of skin layer (SL) and fourth layer (FL) of breast phantom dose during Chest CT using $1.1 \mathrm{~mm}$ and 2.2 mm Bismuth polyurethane(BPC) $10 \%$ and $15 \%$ shields.

\begin{tabular}{|c|c|c|c|c|}
\hline $\begin{array}{l}\text { Percent } \\
\text { Bismuth }\end{array}$ & $\begin{array}{l}\text { thicknece of } \\
\text { shield }(\mathrm{mm})\end{array}$ & $\begin{array}{l}\text { TLD Dose } \\
\text { (mSv) }\end{array}$ & \begin{tabular}{|c|} 
Dose \\
Reduction \\
$(\%)$
\end{tabular} & $\begin{array}{l}\text { statistic } \\
\text { anlalyses }\end{array}$ \\
\hline & $\begin{array}{l}\text { Without } \\
\text { shield }\end{array}$ & $\begin{array}{ll}\text { SL } & 8.32 \pm 2.03 \\
\text { FL } & 7.63 \pm 1.20\end{array}$ & --- & --- \\
\hline \multirow{2}{*}{$10 \%$} & 1.1 & $\begin{array}{ll}\text { SL } & 3.74 \pm 0.16 \\
\text { FL } & 4.32 \pm 0.26\end{array}$ & $\begin{array}{c}55 \\
43.3\end{array}$ & \multirow{2}{*}{$\begin{array}{l}p<0.05 \\
p<0.05 \\
p<0.05 \\
p<0.05\end{array}$} \\
\hline & 2.2 & $\begin{array}{ll}\text { SL } & 2.57 \pm 0.25 \\
\text { FL } & 4.22 \pm 0.28\end{array}$ & $\begin{array}{l}69.1 \\
44.7\end{array}$ & \\
\hline \multirow{2}{*}{$15 \%$} & 1.1 & $\begin{array}{ll}\text { SL } & 3.20 \pm 0.43 \\
\text { FL } & 3.97 \pm 0.40\end{array}$ & $\begin{array}{c}61.5 \\
47.96\end{array}$ & \multirow{2}{*}{$\begin{array}{l}p<0.05 \\
p<0.05 \\
p<0.05\end{array}$} \\
\hline & 2.2 & $\begin{array}{ll}S L & 1.87 \pm 0.68 \\
F L & 3.60 \pm 0.05\end{array}$ & $\begin{array}{l}77.5 \\
52.8\end{array}$ & \\
\hline
\end{tabular}




\section{Image quality}

The average increasing of image noises were $9.20 \%, 9.43 \%$ by BPC $10 \%$ and $15 \%$ in breast area, in comparison with no shield using in chest CT image. Also the measured average noise values in mediastinum area were $13.00 \%$ and $15.44 \%$, for $10 \%$ and $15 \%$ of BPC respectinely (Figure 3). In comparison to persence and absence of the BPC shields on the noise imaging was showed increaseing that happened while the noise was not significant in the breast and mediastinum locations when BPC shield was added $(\mathrm{P}>0.05)$. Also CNR was caculated $22.89 \%$ and $23.53 \%$ for $10 \%$ and $15 \%$ BPC shields, respectively.

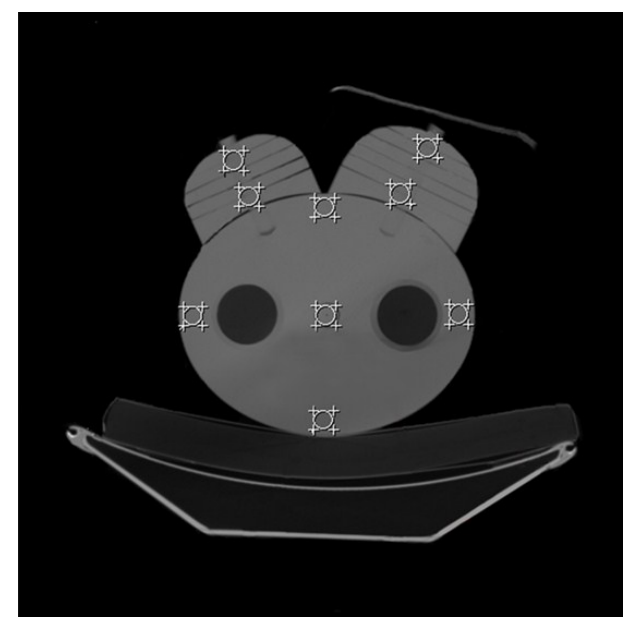

Figure 3. The CT gram presented for image analysis of with and without Bismuth-Polyurethane shields on the chest phantom with selected ROIs. The average $\mathrm{HU}$ value and noise were determined for the marked places with an area of 1.9 $\mathrm{cm} 2$.

\section{DISCUSSION}

Peresent study examed different stages of construction of polyurethane matrixes with the bismuth microparticles capabality of these composite shields for breast protection during chest CT. Also, the different resulting effects upon changing the Bismuth percentages in the Polyurethane matrixes were observed. Results showed that BPC shield have a good potential for reducing breast radiation dose in 10\%, 15\% of Bismuth in 1.1 and $2.2 \mathrm{~mm}$ thicknesses.

By increasing thickness from 1.1 to $2.2 \mathrm{~mm}$ of the BPC shield, a higher dose reduction is made possible for skin and fourth layers. Also, in the $15 \%$ BPC shield, the variation in dose reduction value is considered to be $41.56 \%$ ((3.201.87)/3.20) and 9.31\% ((3.97-3.60)/3.97) for skin and fourth layers, respectively. In the present study using BPC shield have showed that $(\mu)$ and $(\mu / \rho)$ were more than BSC shield $(20)$.

Application of BSC (1 mm thickness) for breast shield on the four location of female chest phantom recorted by TLD showed $12 \%$ dose reduction (21). The highest reduction doses were recorded in the skin layer by BPC shields, at $15 \%$, and a thickness of $2.2 \mathrm{~mm}$. Another study, through 5\% BSC and BPC, breast dose decline for skin and fourth layers proved to be about twice as different for the two types of shields (22). Affect of the Bismuth particle size on the protection of organs explaned (23). Also nano Bismuth shield $(50 \mathrm{~nm})$ showed a dose reducton of $7.2 \%$ and $13.8 \%$ for $0.5 \mathrm{~mm}$ and $1 \mathrm{~mm}$ thicknesses, respectively (24).

In the current study, scout topogram was performed before placing the shields in BPC as well as TLD, when performing CT examinations of the thorax with AEC modulation. The problem is enhanced when the scanner detects increased density due to the presence of the BPC shield, automatically raising the power to achieve optimum imaging. Nowadays, almost all new CT scanners use automatic tube current modulation for dose reduction purposes (25). The operator should notice if the selection of AEC system agrees with BPC shield before topogram, so that there is optimal decline in radiation doses. Also, in this study, the last Bismuth percentage was $15 \%$, because selecting more than $15 \%$ of bismuth beads was not possible and adding more Bismuth to the composite matrix would trigger a saturation mode in polymer matrixes, with the complex not mixed and constructed properly. Unfortunatly, we could not find any similar studies to compare our constructed shields with other similar composites. Most of them used F\&L company shields without details of the compounds such as weighting factor or matrix properting used.

Results showed that in chest CT, the breast's highest dose was recorded at the skin layer, and the lowest dose at the fourth layer in the

Int. J. Radiat. Res., Vol. 19 No. 2, April 2021 
phantom without shield, but in BPC shieds, less effective radiation protection was observed in the fourth (deep) layer of the breast, in comparison with the skin layer. The potential of Bismuth shields for dose reduction in different layers has been explained in a few articles. These studies have shown that in dose decline is better in the skin layer $(26,27)$. A study demonstrated that using Bismuth shields induces declines in the doses of superficial organs (11). However, the fact that the breast's glandular tissue is the most sensitive and was placed with a distinct distance from the surface of the skin is cause for finding a method with good performanc shield effect. Also, there are some studies that did not measure the radiation dose in the glandular tissue, but pointed out lower doses in the deeper portions of the breast because of X-ray attenuation of the breast tissue itself $(2,9,12)$.

It should be noted that, when using bismuth shields for superficial organs, the dose recorded in the deeper layers of the breast was higher than the skin layer, while the dose without shielding in deeper layer was lower in comparison with the skin layer $(11,26)$. One possible reason for the difference in dose reduction in the two layers (skin and fourth) of the breast is the role of shields as a filter for lower, $\mathrm{kVp}$, energy of X-ray polyenergetic beam that triggers decreases in breast skin dose, while the deep layers of the breast received harder $\mathrm{X}$-Ray beams (28).

The image quality variation in Bismuth shields is one of the most important factors in its use in radiology. Using BPC $15 \%$ with a thickness of $1.1 \mathrm{~mm}$ contributed to $61.5 \%$ breast dose reduction in the skin layer, while image noise in the breast area and mediastnum increased to $9.43 \%$ and $15.44 \%$, respectively. With the application of bismuth shields for phantom in the chest CT scan, Vollmar et al. obtained a reduction in breast dose and increasing of image noise $50 \%$ and $40 \%$ respectively (29).

Other studies showed that, with the application of various commercial breast shields (details of shields are not presented), dose reductions in the breast were $16-37.5 \%$ (1), 55\%
(28), 26\% (8), and increases in noise were 19\%-40\%, 42\%-43\%, respectively. Coursey et al. showed a diffrentiation of noise in the range of 10.0 to $13.1 \mathrm{HU}{ }^{(8)}$. Also, Servas et al. used a Bismuth breast shield on a 5-year-old phantom in chest CT and reported that dose reduction and increased $\mathrm{HU}$ were $15 \%$ and $4-6 \mathrm{HU}$, respectively (30). In our study, maximum different values of CT numbers (HU) in the breast area and mediastinum with and without shielding were $2 \mathrm{HU}$ and $4 \mathrm{HU}$, respectively.

\section{CONCLUSION}

Application of BPC shields as well as changing the bismuth percentages in composites, thickness and type of matrixes are effective factors in reducing breast dose significantly. Thus, bismuth shields with Polyurethane composites have the potential for high rates of dose reduction, are adequate protective shields against radiation effects, and can reduce the risk of breast cancer when engaged in chest CT.

\section{ACKNOWLEDGMENT}

This work was supported by the office of the vice president as a novel and technical project for research at the Tabriz University of Medical Sciences in Iran.

\section{Conflicts of interest: Declared none.}

\section{REFERENCES}

1. Kim YK, Sung YM, Choi JH, Kim EY, Kim HS (2013) Reduced radiation exposure of the female breast during low-dose chest CT using organ-based tube current modulation and a bismuth shield: comparison of image quality and radiation dose. Am J Roentgenol, 200: 537-544.

2. Tappouni R and Mathers B (2012) Scan quality and entrance skin dose in thoracic CT: a comparison between bismuth breast shield and posteriorly centered partial CT scans. ISRN radiol doi.org/10.5402/2013/457396. ISRN, 2013: 1-6. 
3. Parker M, Kelleher N, Hoots J, Chung J, Fatouros P, Benedict $S$ (2008) Absorbed radiation dose of the female breast during diagnostic multidetector chest CT and dose reduction with a tungsten-antimony composite breast shield: preliminary results. Clinic Radiol, 63: 278-288.

4. Colletti PM, Micheli OA, Lee KH (2013) To shield or not to shield: application of bismuth breast shields. $A m$ J Roentgenol, 200: 503-507.

5. Mettler Jr FA, Huda W, Yoshizumi TT, Mahesh M (2008) Effective doses in radiology and diagnostic nuclear medicine. A Catal Radiol, 248: 254-263.

6. Gorycki T, Lasek I, Kamiński K, Studniarek M(2014) Evaluation of radiation doses delivered in different chest CT protocols. Polish J Radiol, 79: 1-5.

7. Kazempour M, Saeedimoghadam M, Shooli FS, Shokrpour N (2015) Assessment of the radiation attenuation properties of several lead free composites by Monte Carlo simulation. J Biomed Phys Eng, 5: 67-76.

8. Coursey C, Frush DP, Yoshizumi T, Toncheva G, Nguyen G, Greenberg SB (2008) Pediatric chest MDCT using tube current modulation: effect on radiation dose with breast shielding. Am J Roentgenol, 190: 54-61.

9. Kalra MK, Dang P, Singh S, Saini S, Shepard JAO (2009) Inplane shielding for $\mathrm{CT}$ : effect of off-centering, automatic exposure control and shield-to-surface distance. Korean $J$ Radiol, 10: 156-163.

10. Seoung YH (2015) Evaluation of Radiation Dose Reduction during CT Scans Using Oxide Bismuth and Nano-Barium Sulfate Shields. J Korean Phys Soc, 67:1-6.

11. Yilmaz MH, Albayram S, Yasar D, Özer H, Adaletli I, Selçuk $D$, et al. (2007) Female breast radiation exposure during thorax multidetector computed tomography and the effectiveness of bismuth breast shield to reduce breast radiation dose. J Compt Assist Tomogr, 31: 138-142.

12. Lambert JW and Gould RG (2016) Evaluation of a net dosereducing organ-based tube current modulation technique: comparison with standard dose and bismuth-shielded acquisitions. Am J Roentgenol, 206: 1233-1240.

13. Wang J, Duan X, Christner JA, Leng S, Yu L, McCollough CH (2011) Radiation dose reduction to the breast in thoracic $\mathrm{CT}$ : Comparison of bismuth shielding, organ-based tube current modulation, and use of a globally decreased tube current. Med Phys, 38: 6084-6092.

14. Ciarmatori A, Nocetti L, Mistretta G, Zambelli G, Costi T (2016) Reducing absorbed dose to eye lenses in head CT examinations: the effect of bismuth shielding. Australas Phys Eng Sci Med, 39:583-589.

15. Heaney DE and Norvill CAJ (2006) A Comparison of reduction in CT dose through the use of gantry angulations or bismuth shields. Australias Phys Eng Sci Med, 29: 172-178.

16. Fricke BL, Donnelly LF, Frush DP, Yoshizumi T, Varchena $V$, Poe SA, et al. (2003) In-plane bismuth breast shields for pediatric CT: effects on radiation dose and image quality using experimental and clinical data. Am J Roentgenol, 180: 407-411.

17. Alonso TC, Mourão AP, Santana PC, da Silva TA (2016) Assessment of breast absorbed doses during thoracic computed tomography scan to evaluate the effectiveness of bismuth shielding. Appl Radiat Isoto, 117: 55-57.

18. Mendes $M$, Costa F, Figueira $C$, Madeira $P$, Teles $P$, Vaz $P$ (2015) Assessment of patient dose reduction by bismuth shielding in CT using measurements, GEANT4 and MCNPX simulations. Rad Prot Dosim, 165: 175-181.

19. Mehnati P, Ghavami M, Heidari H (2017) Reducing radiation doses in female breast and lung during CT examinations of thorax: A new technique in two scanners. J Biomed Phys Eng, 7: 217-224.

20. Mehnati P, Arash M, Zakerhamidi M S, Ghavami M. Designing and Construction of Breast Shields using Silicone Composite of Bismuth for Chest CT. Int J Radiat Res, 17: 491-496.

21. Mehnati $P$, Malekzadeh R, Yousefi Sooteh M, Refahi $S$ (2018) Assessment of the efficiency of new bismuth composite shields in radiation dose decline to breast during chest CT. Egyptian J Radiol Nucl Med, 49: 1187-1189.

22. Mehnati $P$, Arash M, Akhlaghi $P$ (2018) Bismuth-silicon and bismuth-polyurethane composite shields for breasts protection in chest computed tomography examinations. J Med Phys, 43: 61-65.

23. Malekzadeh R, Mehnati $P$, Yousefi Sooteh M, Mesbahi A (2019) Influence of the size of nanoland microparticles and photon energy on mass attenuation coefficients of bismuth-silicon shields in diagnostic radiology doi.org/10.1007/s12194-019-00529-3. Radiol Phys Technol, 12: 325-34.

24. Mehnati P, Yousefi Sooteh M, Malekzadeh R, Divband B, Refahi S (2019) Breast Conservation from Radiation Damage by Using Nano Bismuth Shields in Chest Computed Tomography Scan. Cres J Med Biol Scien 6: 46-50.

25. Sargazi V and Mehnati P (2014) STERATEGIS FOR BREAST DOSE REDUCTION IN CHEAST CT SCAN. Int J Anal, Pharm Biomed S, 3: 66-72.

26. Mehnati P, Malekzadeh R, Yousefi Sooteh M (2019) Use of bismuth shield for protection of superficial radiosensitive organs in patients undergoing computed tomography: a literature review and meta-analysis. Radiol Phys and Technol, 12: 6-25.

27. Hohl C, Wildberger J, Süß C, Thomas C, Mühlenbruch G, Schmidt T, et al. (2006) Radiation dose reduction to breast and thyroid during MDCT: effectiveness of an in-plane bismuth shield. Acta Radiol, 47: 562-567.

28. Hurwitz LM, Yoshizumi TT, Goodman PC, Nelson RC, Toncheva G, Nguyen GB, et al. (2009) Radiation dose savings for adult pulmonary embolus 64-MDCT using bismuth breast shields, lower peak kilovoltage, and automatic tube current modulation. Am J Roentgenol, 192: 244-253.

29. Vollmar SV and Kalender WA (2008) Reduction of dose to the female breast in thoracic CT: a comparison of standard -protocol, bismuth-shielded, partial and tube-currentmodulated CT examinations. Eur radiol, 18: 1674-1682.

30. Servaes $S$ and Zhu X (2013) The effects of bismuth breast shields in conjunction with automatic tube current modulation in CT imaging. Ped Radiol, 43: 1287-1294.

Int. J. Radiat. Res., Vol. 19 No. 1, April 2021 